\title{
A spatial computational hybrid model to understand the level of migration across metropolitan areas in Mexico
}

\author{
Estela Rivero Fuentes* \\ Marcos Valdivia López ${ }^{* *}$
}

Recepción: 5 de abril de 2017 Aceptación: 14 de julio de 2017

Resumen México ha experimentado un descenso en su tasa de migración interregional desde la década de los setenta del siglo pasado. Esta disminución ha venido acompañada de un aumento en la migración intermetropolitana y una diversificación de los flujos. En este documento analizamos esta migración utilizando un modelo computacional de agentes que interactúan, integrado con información de sistemas de información geográfica. Este modelo considera que las decisiones de los migrantes dependen en gran medida de los servicios y de otras características urbanas, en un contexto de racionalidad limitada o acotada. Los resultados de las simulaciones son consistentes con una distribución más dispersa de los migrantes. Nuestros resultados indican que las decisiones de migración interna se restringen a un grupo pequeño de áreas metropolitanas. Estos hallazgos apoyan la hipótesis de que no es posible lograr un equilibrio espacial cuando los migrantes son indiferentes entre locaciones.

PALABRAS CLAVE: migración interna, áreas metropolitanas, migración intermetropolitana, servicios, modelo computacional.

Abstract Mexico has experienced a secular decline in its interregional rate of migration since 1970, which has been accompanied by an increase in intermetropolitan migration and a diversification of the flows. In this document, we analyze these phenomena through a computational model of interactive agents integrated with GIS. The modeling strategy adopted in this research considers that migrants' decisions depend strongly on

\footnotetext{
* Investigadora en Salud y Demografía (INSAD), estelariv@insad.com.mx

** InvestigadordelCentro Regionalde Investigaciones Multidisciplinarias (CRIM), UMAM, marcosv@correo.crim.unam.mx
} 
amenities and other urban characteristics in a context of limited or bounded rationality. Key simulation results are consistent with a less concentrated distribution of migrants. Our results indicate that internal migration decisions can be restricted to no more than a small group of local metropolitan areas. Therefore, it is not possible to argue for a spatial equilibrium where migrants are indifferent across locations.

KEY WORDS: internal migration, metropolitan areas, intermetropolitan migration, amenities, computational model.

\section{Introduction}

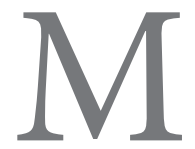

exico has experienced a secular decline in its interregional rate of migration since 1970, with parallelisms to the ones exhibited in the USA and other countries. The growing importance of urban areas as a place of origin and of destination of migrants has accompanied the decline in migration rates. One consequence of this has been that inter-urban migration, including intermetropolitan migration is nowadays the single-most important type of migratory flow in Mexico (see Pérez \& Santos, 2013; Sobrino, 2010). ${ }^{1}$

One characteristic of intermetropolitan migration in Mexico is that it follows very strong spatial patterns. Several different econometrical methodologies can be used to try to describe and predict the spatial distribution of intermetropolitan migrants in Mexico. One common limitation of these methodologies is that they have difficulties to incorporate the heterogeneity of the decision-makers in a dynamic setting. Another limitation is that in analytical settings it is very difficult to track how the spatial distribution of migrants changes, as the rules for individuals' decision making process (the rules) and the setting (the parameters) are changed. This is more easily done with a computational approach that allows the simultaneous manipulation of the parameters and the rules.

In this paper, we propose a spatial computational hybrid migration model that considers the influence of amenities and other urban characteristics in migrants' decisions to analyze inter-metropolitan migration. Heterogeneity in our model means that potential migrants have limited — and differentiated - information about the conditions in the metropolitan areas they can move to. We rely on a sort of agent based modeling integrated with GIS such that potential migrants are embedded in actual urban landscapes that represent the 56 metropolitan areas in Mexico. In our model, 2005-2010, it represented 29.1 \% (Pérez \& Santos 2013). 
potential migrants decide whether to enroll in intermetropolitan migration, and where to go to, in function of how close they are to an important metropolitan area (proximity to the urban hierarchy), economic activity and urban amenities of sending and receiving metropolitan areas.

Relying on econometric estimations and simulations, we find that amenities are key in shaping the actual distribution of intermetropolitan migrants across metropolitan areas. Our simulations provide important insights about how this distribution would change if amenities were to become more important over time. Our modeling strategy helps to explain why the distribution of migrants has diversified - which seems to run along the lines of the spatial equilibrium hypothesis (Evans 1990, Glaeser \& Gottlieb 2009). Nevertheless, our results suggest that intermetropolitan migrants make their migratory decisions in a context of bounded rationality, where amenities and proximity to urban-hierarchy are very relevant. This makes the spatial equilibrium hypothesis - i.e., that migrants are indifferent across destinations—unlikely to hold.

The paper is structured as follows: Sections I and II provide the theory and background information necessary to understand our model and the results we obtain. In section III we describe the computational model that we use to understand inter - metropolitan migration, while in section IV we discuss its key results. In the concluding section we discuss the future policy and methodological implications of our results.

\section{How do agglomeration economies and amenities help to explain internal migration? A brief literature review}

Many different theories have been used to explain internal migration and migrants' destinations. Most of these assume that the decision to migrate is made at the individual or household level and imply that individuals move because there are different income and employment opportunities (see among others Greenwood, 1985; Stark \& Levhari, 1982; Todaro, 1980). However, more recent developments complement these perspectives with the argument that agglomeration economies and amenities are key in the understanding of migration flows. In this document, we focus on these explanations. In order to understand them, it is a priority to define the concept of agglomeration economies. These are commonly understood as a clustering of economic activity and they occur in urban areas (Brakman et al., 2009). There are three different perspectives about the relationship between agglomeration economies and migration. The main distinctions between them lie on their 
understanding of the origin of agglomeration economies, on how these relate dynamically with labor, and consequently, on the direction of the causal association between agglomeration economies and migration, and on which are the factors of the agglomeration economies that they consider attractive to migrants.

The first of these perspectives is attached-to the New Economic Geography (NEG)-see Krugman, 1991; Crozet, 2004-, and its proposal is commonly summarized in the literature as "migrants follow the market potential." This proposal claims that agglomeration economies are particularly attracting to migrants because of their high market potential, their capability to attract factors of production (including firms and workers), and their reduction of transportation costs (Brackman et al., 2009). ${ }^{2}$ Under this perspective, it is said that in a context of agglomeration economies, "persons (or migrants) follow firms" once firms have chosen where to locate. An empirical application of this perspective can be found in Crozet (2004), who through an econometric approximation explained migration flows in Europe. In his model, Crozet incorporated, among other variables, the expected wage or salary of the place of destination, costs of mobility, and a variable that identified the market potential of the region.

In the second of these perspectives, individuals can base their mobility decisions on the consumption of non - tradable goods that can be natural (weather, proximity to coasts) or urban (life style, cultural facilities, service facilities, etc.). Since these goods are commonly known as amenities, this is also known as the amenity approach. Amenities have, in general, an uneven regional distribution, being this the reason why they are internalized in specific prices, such as housing prices. Under this perspective, "firms follow persons". ${ }^{3}$ Recently, the amenity approach is leaded by authors like Florida $(2003,2005)$ and Glaeser and colleagues (e.g. Glaeser, Kolko \& Saez, 2001; Glaeser \& Gottlieb, 2009), who state that agglomeration economies - and metropolitan areas in general-draw migrants in with high human capital because of different attracting factors (associated to the amenities) they have to offer.

Florida's proposal, known as "the creative class theory", propounds that individuals who work in knowledge -intensive sectors and artists, which he calls "the creative class", are attracted by a city's tolerance-level. Hence, in Florida's theory,

2 It is important to notice the similarity between the implications of this and the following proposals, and those of the traditional neoclassical economics explanations of migration (see Greenwood, 1985; Stark \& Levhari 1982; Todaro, 1980). The difference between the two approaches is that in the case of the proposals that are based in agglomeration economies, the explanation is based on a theory of localization of both firms and workers.

3 Authors like Rosen (1979) and Roback (1982) were the first to use an amenity perspective to analyze economic variables such as production, employment and prices in a spatial equilibrium framework. 
the main attracting amenity is tolerance- which implies that the more tolerance a city has, the more it will attract creative individuals. However, since tolerance is difficult to observe directly, the concept is operationalized through the presence of bohemians, artists, immigrants and members of the gay and lesbian community in a location (Florida, 2003, 2005).

Glaeser and colleagues' proposal relates to Florida's creative class theory in the sense that they also put forward the idea that high-skilled individuals are driven to urban areas by specific attracting factors. In their proposal, these are climate and urban amenities that improve the quality of living, such as high - quality schools, hospitals, museums, and theaters and other places of recreation. A key concept in this discussion is the spatial equilibrium hypothesis that establishes that individuals or migrants would be indifferent across locations. In particular, spatial equilibrium implies the following relationship: Urban productivity premium (wages) + Urban amenity premium = Urban Rent Premium (Glaeser et al., 2001); and the main idea behind this is that "the effect of wages on cities plus the effect of amenities on cities must be offset by the effect of cities on housing prices" (Glaeser et al., 2001, p. 31). For this reason, Glaeser and colleagues consider that it is important, when deciding whether or not an urban area is attractive, to take into account its housing prices and its crime rate (see Glaeser, Kolko \& Saez, 2001; Glaeser \& Gottlieb, 2009; Storper \& Scott, 2009). Florida, Glaeser, and their colleagues argue that the concentration of high-skilled human capital in certain areas is a key factor in the development of urban centers. Three mechanisms that make this happen are knowledge spillovers, the fact that being close to other creative people propels creativity, and increased labor supply (Florida, 2003, 2004; Glaeser, Kolko \& Saez, 2001; Glaeser \& Gottlieb, 2009).

The third perspective can be labelled the economic sociology or political economy perspective, and is represented, among others, by Storper (2013), Storper \& Scott (2009), and other related authors such as Caballero \& Richard (1992); Chan, Been-Lon \& Kee-Nam (1995); and Segoura, (1996). These authors claim that for deciphering the relationship between agglomeration economies and labor it is important to understand the spatial logic of production, which they propose similar to that advanced by the NEG approach á la Krugman. That is, these authors argue that the relationship between agglomeration economies and labor is completely dynamic, and depends on external economies (also known as Marhallian externalities). External economies are the location benefits that firms obtain from being close to other firms, such as knowledge spillovers, geographical proximity to specialized suppliers - which decreases transportation costs, and increased labor supply (see for example Caballero \& Lyons 1992; Chan, Chen \& Cheung, 1995; Segoura, 1996). But the economic sociology perspective differs from the NEG 
perspective because the first emphasizes the historical understanding of the spatial logic of production and the dynamic relationship between agglomeration economies and labor: agglomeration economies do not emerge arbitrarily, but rather where there is an agglomeration of skilled labor with certain characteristics that facilitate the emergence of specific industries (Storper \& Scott, 2009). Furthermore, Storper \& Scott (2009) claim that once agglomeration economies are functioning, the dynamic they follow is similar to a process of circular and cumulative causation: the more the local industries output grows, the more it will attract labor, and with greater labor market inputs, the greater the output will be.

Storper \& Scott's (2009) asseverations have several important methodological implications for the purposes of this study, because they claim that the causal relationship between immigration and externalities works through job creation. Therefore, once employment opportunities are controlled for in a econometric setting, the statistical relationship between amenities and migration will only be marginally significant (Storper \& Scott, 2009).

Finally, it is important to mention how these theories, in special the amenity approach, have been used directly or indirectly to understand the dynamics of internal migration, and in particular, its secular decline in some regions of the world. In a recent paper, Partridge et al., (2012) test the hypothesis that the descent of internal migration that has been observed in the USA since the postwar years can be an indication of a tendency to spatial equilibrium. In specific this hypothesis would mean that amenities and proximity to urban hierarchy are becoming less influential in internal migration flows, because they have been capitalized in prices making "interregional utilities levels more equal". Nevertheless, Partridge et al., do not find empirical evidence to support the spatial equilibrium thesis, suggesting that natural and urban amenities continue to have an effect on the preference for some destinations. These authors' results also suggest that local labor markets are another important factor in the explanation of the decline of internal migration in the USA.

Just as the USA and other countries, Mexico has also experienced a recent decline in inter-regional migration, which has also been accompanied by an increase in the importance of intermetropolitan migration (Partida, 2013; Pérez \& Santos, 2013; Sobrino, 2007, 2010). Since this kind of movement is becoming the dominant migration in the country, we focus our study in this flow. The empirical evidence available at the moment seems to indicate that intermetropolitan migration in Mexico is not approaching a spatial equilibrium, because it is still highly concentrated in a few destinations. Studies that analyze the importance of amenities in internal migration in Mexico are scarce. Those that exist seem to indicate that amenities have a role in migration destinations. For example, Vera Noriega (2006) claims that when agricultural migrants move as a family with children, they choose 
destinations with the largest number of amenities and child care facilities, even when these are not the highest paying. Something similar was found by Zentella Chavez (s.d.) among Mazatec migrants to Mexico City.

To analyze the potential paths of how the distribution of intermetropolitan migrants will evolve in the future, in section 3 we propose a hybrid agent based model integrated with GIS that incorporates some of the key theoretical elements discussed above. In this simulation model we incorporate the effect of amenities, proximity to urban hierarchy and agglomeration economies. Furthermore, as migration decisions have been demonstrated to be made under a boundedrationality framework, where migrants only know about a number of destinations (see for example Rivero, 2012), we incorporate this in our simulations through metropolitan information networks. In our simulations we use data from the 2000 National Population Census (INEGI, 2000) because it was during the period 19952000 that the changes in migration destinations, and a tendency towards the metropolization of migration were first noticed (Sobrino, 2010).

\section{Stylized facts}

Mexico has experienced a decline in its rate of migration across states since 1970: in that year the rate of migration was 11.7 migrants per one thousand inhabitants, while in 2010 the rate was 5.9 (Sobrino, 2011). This stylized fact is also observed in the USA, where the rate of migration has systematically declined since the post-war period both at the state and the county level (Partridge, 2012). In terms of the 56 metropolitan areas of Mexico, the migration rate has also declined but this decline has not been as steep as it has been in other areas of the country. Since urban fertility and mortality rates in Mexico have been similar in the last three decades, internal migration has been signaled as the main factor behind differentials in urban growth (Conapo, 2007). Figure 1, which shows the population growth in the 56 metropolitan areas (measured as log Pobt - log Pobt-1) in the periods 2000-2005 and 20052010 , confirms a considerable reduction in the dispersion of the population growth during the 2005-2010 period. The median population growth of the two periods is approximately the same $(0.1$, which means that half the metropolitan areas grew less than $10 \%$ and half grew more). However, if one looks at figure 1, one will see that the extremes of the distribution and the width of the quartiles expand more during the period 2000-2005 than during the period 2005-2010. Something else to notice in figure 1 is that while in the period 2000-2005 there were some metropolitan areas that decreased its size (with negative rates of growth), this did not happen in the most recent period. 


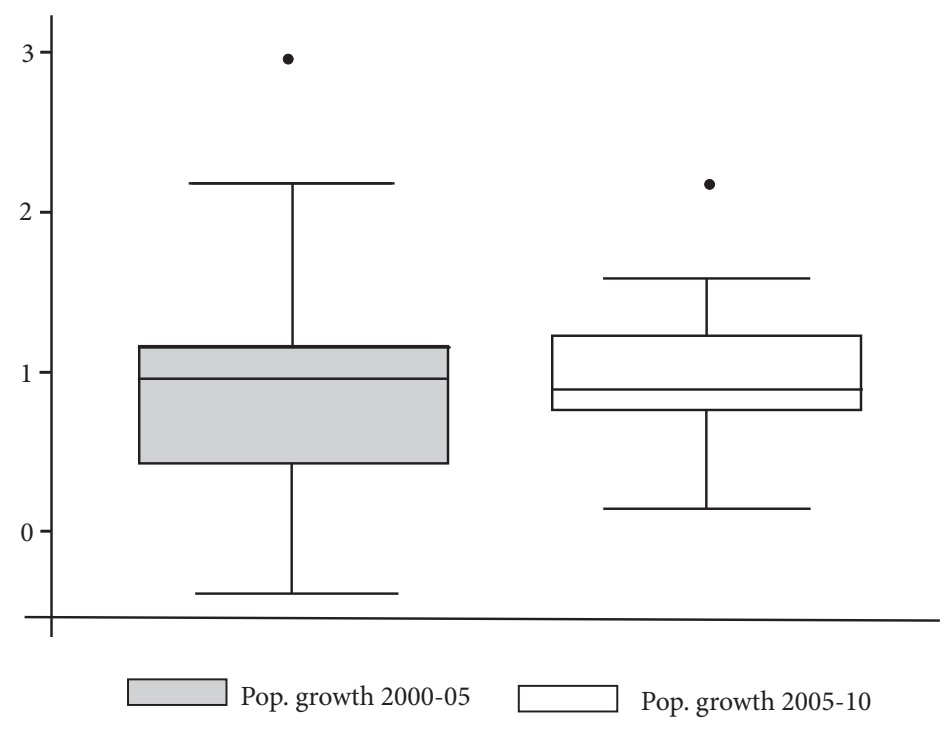

Note: population growth measured as $\log \operatorname{Pob}_{\mathrm{t}}-\log \operatorname{Pob}_{\mathrm{t}-1}$

Source: Census date 2000, 2010 (INEGI).

As we mentioned in the literature review section, one of the most novel approaches to explain the decline in internal migration is the spatial equilibrium approach (Partridge, 2012). When spatial equilibrium is being approached, all individuals are indifferent across locations, and amenities would not be associated with population growth through migration in metropolitan areas, because these would be capitalized in prices (housing prices and wages) (Partridge, 2012). Figures 2 and 3 have the objective of exploring whether this is the case in metropolitan areas in Mexico.

Figure 2 shows the relationship between population growth in 2000-2010 (measured in the $y$-axis) and a measure for the amenity premium in 2005 (in the $\mathrm{x}$ axis) in the 56 Mexican metropolitan areas. The indicator of the amenity presented in this figure was estimated indirectly, as suggested by the spatial equilibrium literature (Glaeser et al, 2001). ${ }^{4}$ As this figure shows, there is a moderate positive relation between both variables (notice that if one was to fit a regression line across the scatterplot, it would have a positive slope; the correlation between both variables

This same approach is used later in the simulations. 


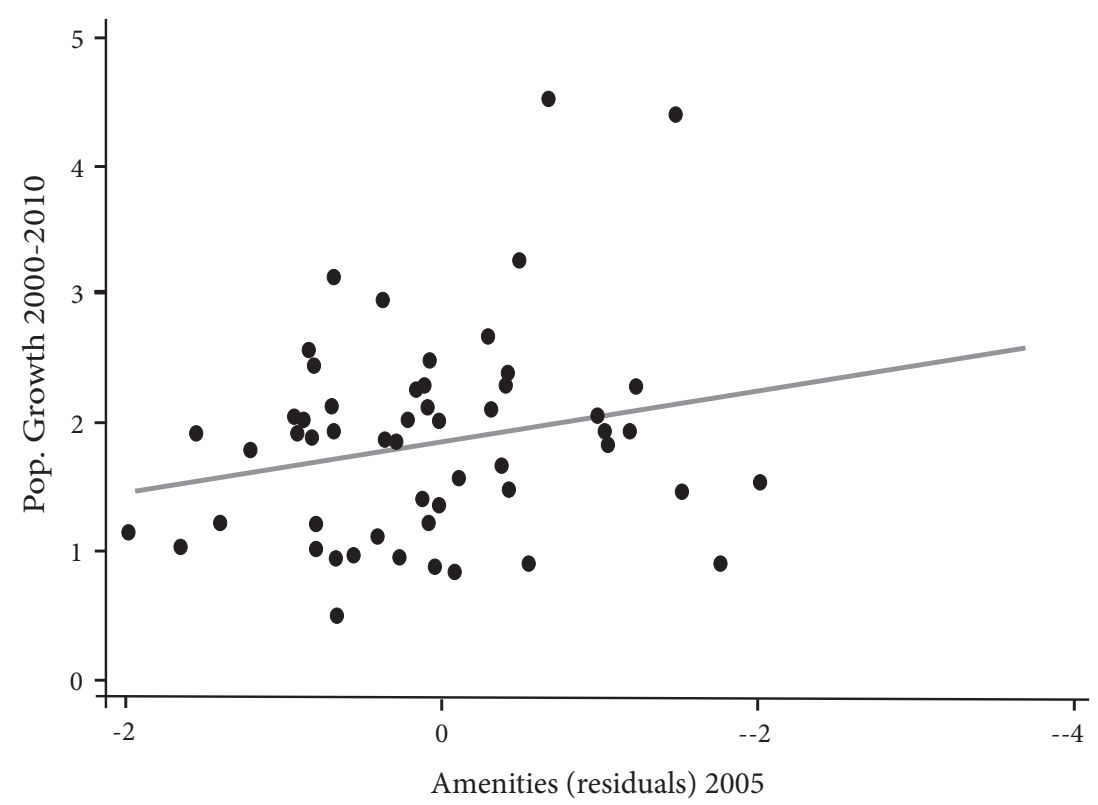

Note: Amenities were calculated as residuals of regressing housing prices on per capita income.

Source: Censo 2000, 2010 (INEGI), Statics from Sociedad Hipotecaria Federal

is 0.25 with a $\mathrm{p} \leq 0.06$ ). This implies that, in general, those metropolitan areas that experienced greater population growth in 2000-2010 were those with a greater amenity premium at the beginning of the period. This empirical relationship also suggests that intermetropolitan migration is far from approaching a spatial equilibrium. ${ }^{5}$ The simulation models in section 3 will help to explore this issue further.

Another form to explore the association between amenities and urban growth due to migration is to analyze the direct association between the share of intermetropolitan migrants and amenities premium - estimated as regression residuals- across 56 metropolitan areas. This is done in figure 3, which shows the

It is important to mention that being far from reaching spatial equilibrium does not imply that the spatial equilibrium framework is invalid. In order to see whether the spatial equilibrium is consistent with the facts -and in particular with the role of amenities- some authors like Glaeser (2008) and Kemeny and Storper (2012) look at the evidence for a strong correlation between high amenities and low real income, since cities with high income are needed to offset low amenities in "unattractive places" (Storper, 2013). 
FIGURE 3. Share of Intermetropolitan Migrants (2010) and Amenities Premium (2005), in Mexican Metropolitan Areas

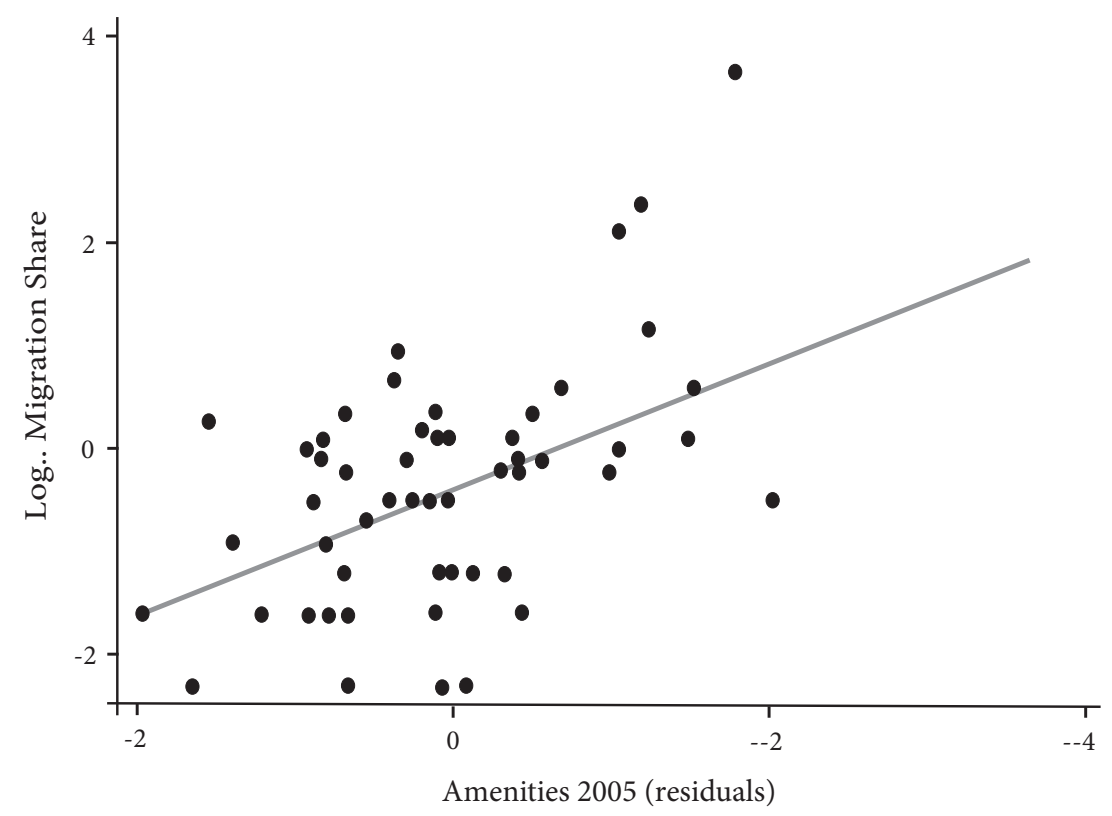

Note: Amenities were calculated as residuals of regressing housing prices on per capita income.

Source: Censo 2000, 2010 (INEGI), Statics from Sociedad Hipotecaria Federal

internal migration share ${ }^{6}$ in the $y$ - axis graphed against the amenities premium (in the $\mathrm{x}$-axis). The association between these two variables is quite positive and much stronger than the one between population growth and amenities. The correlation between both variables is $0.5(\mathrm{p} \leqslant 0.001)$. This further corroborates that amenities could play a role in the dynamics of intermetropolitan migration in Mexico, an issue that we will explore in detail in the next section.

Two of the objectives of this paper are to analyze the relationship between amenities and metropolitan population gain through migration, and to see how this is associated to the diversification of urban migrants' destinations. With these objectives in mind, we present with descriptive purposes, in figure 4 , the annual rate of immigration to metropolitan areas from metropolitan origin (per one thousand inhabitants) for the period 2005-2010, while figure 5 shows the share of

${ }_{6} \quad$ In this paper share of intermetropolitan migrants and internal migration share are used indistinctly. 
metropolitan migrants for the 56 metropolitan areas for the periods 1995-2000 and $2005-2010 .^{7}$ During the 2005-2010 period, the average annual rate of immigration that had a metropolitan origin for the 56 metropolitan areas was 11.3 - see red bar in figure 5. This means that if one were to take all these cities together, each year they would receive 11.3 new immigrants from the metropolitan areas in the study for every 1,000 people that were already living there. ${ }^{8}$ As this is an average, there are metropolitan areas that have a much higher rate of immigration, and ones that have a lower immigration rate. During the 2005-2010 period, Puerto Vallarta, Pachuca, Cancun, Monterrey and Colima are the five metropolitan areas with the highest immigration rates, all receiving more than 15 immigrants per 1,000 inhabitants of the other metropolitan areas. The metropolitan area of Valle de Mexico, which was

FIGURE 4. Annual Rate of Immigration to Metropolitan Areas from Metropolitan Areas per 1,000 inhabitants, Mexico 2005-2010.

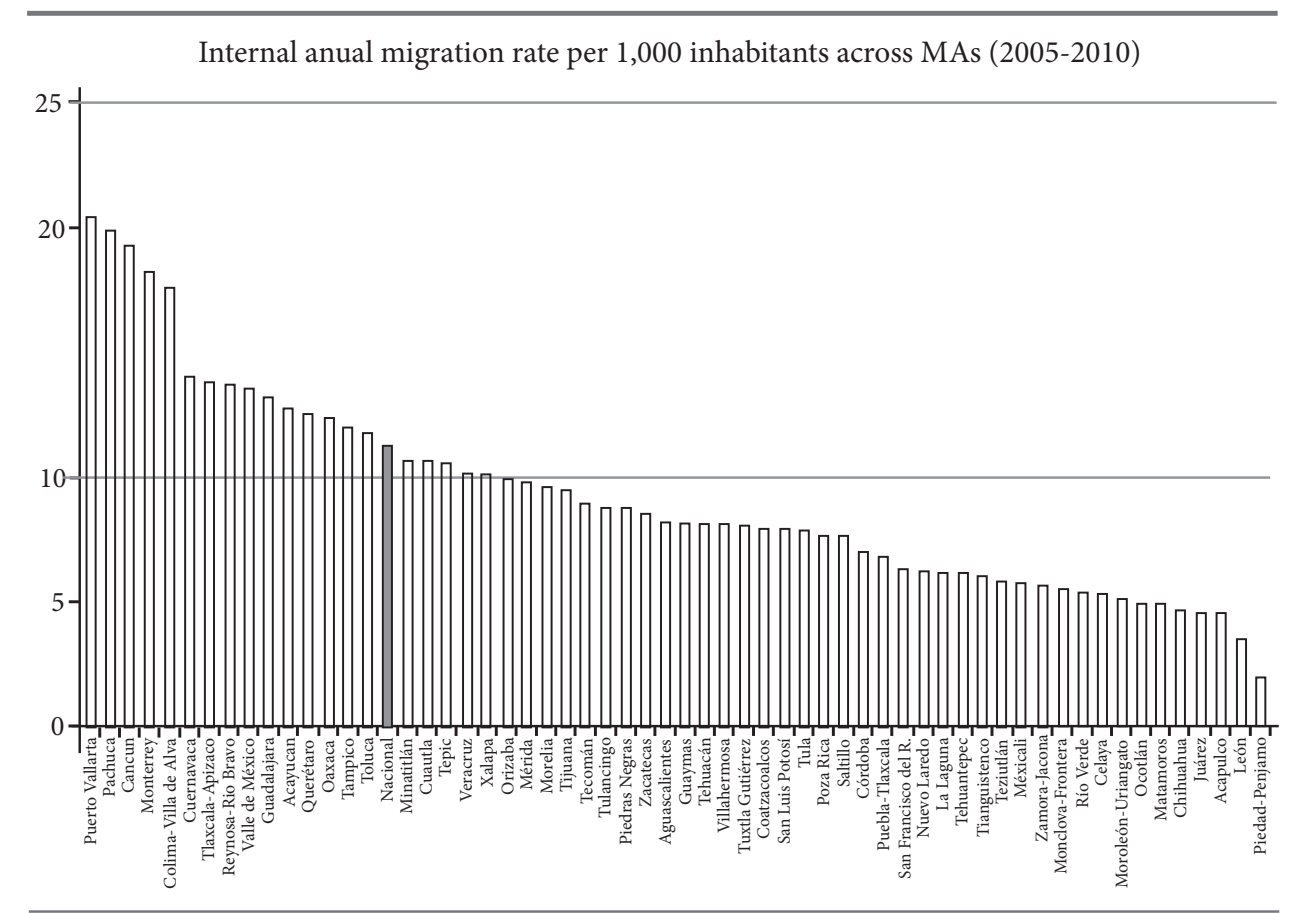

Source: Census 2010 (INEGI)

7 This share of migration was calculated over the total number of migrants of the 56 metropolitan areas.

8 Notice that this average is only for illustration purposes, as in this case the average would be zero because this would be a hypothetical close population. 
the main area of destination for both urban and rural migrants until the 90s (Sobrino, 2010; Rivero, 2012), is now in a group of cities that appear to be the second places of destination and has a rate of 13 immigrants per 1,000 inhabitants. On the lower extreme of the distribution, the number of metropolitan areas that receive less than 10 immigrants per 1,000 inhabitants is large (41), with only eight of them receiving less than 5 immigrants per 1,000 inhabitants. This supports two contrasting arguments: on the one hand, that urban migration is still dominated by a few metropolitan areas which are important attraction places; and on the other, that the rest of the metropolitan areas have a very similar and weak attraction power.

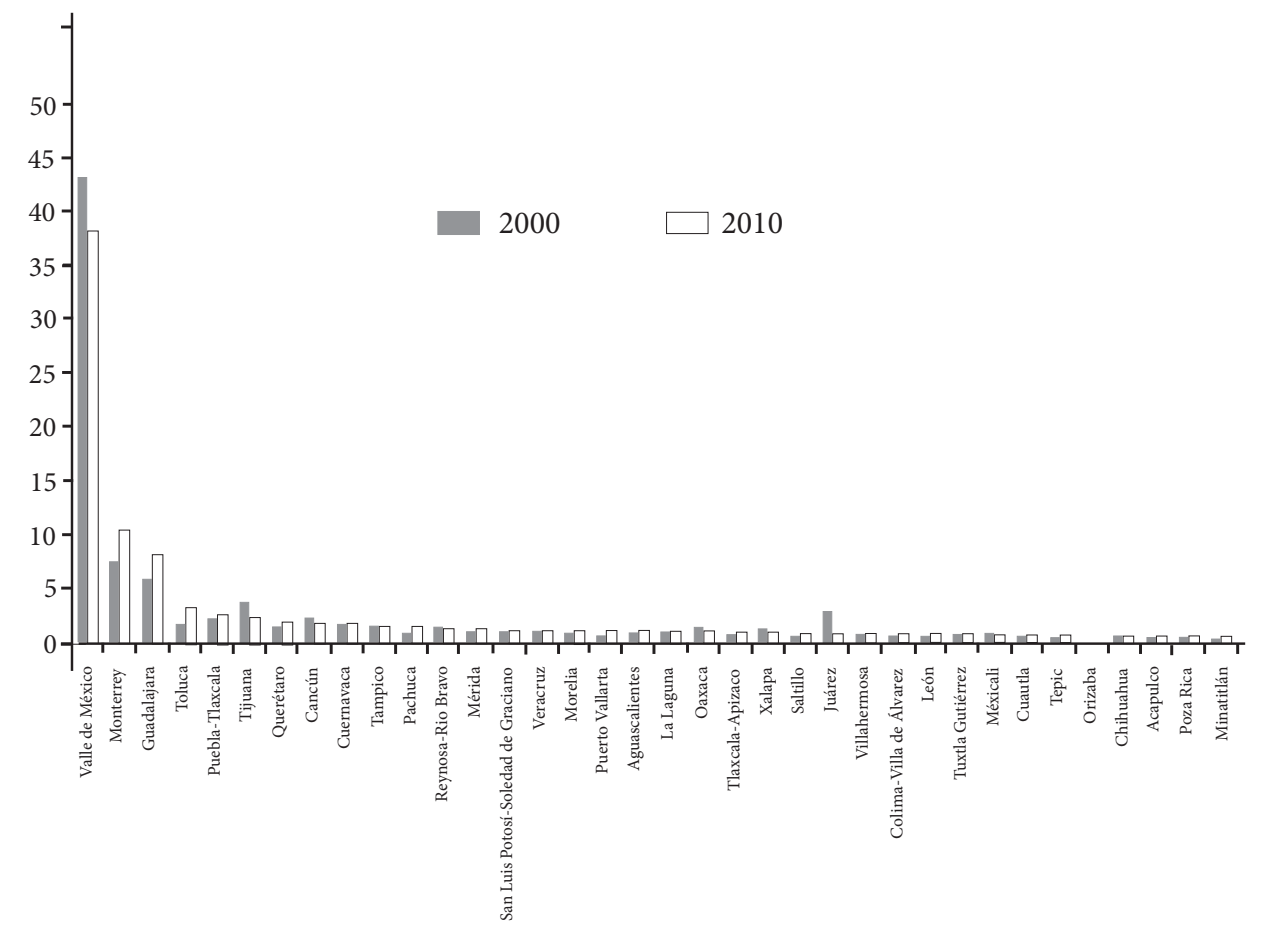

Source: Census 2010 (INEGI)

Figure 5 depicts the share of intermetropolitan migrants for 1995-2000 and 2005-2010 ranked from the highest to lowest share in 2005-2010. This figure shows a clear concentration of the number of migrants in the three largest metropolitan areas of the country, which altogether account for $56 \%$ of the immigrants in the last 
period: Valle de Mexico (37\%), Guadalajara (8\%), and Monterrey (10\%). This concentration, which occurs despite the medium immigration rates of Valle de Mexico and Guadalajara is partially due to the size of these metropolitan areas. The ranking of the concentration share of the three largest metropolitan areas did not change between 2000 y 2010, but Valle de Mexico decreased its share from $43 \%$ in 1995-2000 to 38\% in 2005-2010, while Monterrey and Guadalajara increased both their share in 2.9 and 2.0 percent points respectively. In the same way, other medium-size metropolitan areas such as Toluca, Puebla, Queretaro and Pachuca (which have high immigration rates) have increased its participation share. This process is part of the convergence dynamics that we mentioned above. As a consequence, one would expect that in the long run ${ }^{9}$, the share of intermetropolitan immigrants equalizes across metropolitan areas. This dynamic process will be explored in the next sections with an agent based model integrated with GIS that analyzes migration decisions across metropolitan areas.

\section{Model}

With the goal of analyzing the effect of amenities on metropolitan migration and the distribution of metropolitan migrants, we propose a computational model similar to an agent based approach. In this model we simulate the mobility decisions of migrants over time across metropolitan areas in Mexico. There are several advantages to this approach. One of them is that it enables us to incorporate agent heterogeneity (in this case the information that individuals have about the alternative destinations and the way in which they respond to it) in a dynamic setting. Doing this in an econometric or analytical model with the existing methodologies would be too difficult. A second advantage is that this computational approach allows us to see how the results change as we modify the parameters and rules to which individuals are subject to. In this particular case, we are interested in the effect that the following three factors have on the distribution of metropolitan migrants across metropolitan areas: amenities in each potential destination, the knowledge that migrants may have about destinations and how distance plays in their migration decisions. In our simulations we take the effect of knowledge as a migration rule, which we modify from one simulation exercise to the other. The effect of amenities and distance is approached empirically. To do this, we follow a two-step approach. In a first step, described in the equation (1), below, we implement

9 One of the things this depends on is the size of metropolitan areas. They would need to tend to be, in the long run, of the same size. 
a multivariate statistical model to estimate the relative importance of individual sociodemographic characteristics, the economic conditions and amenities in metropolitan areas, and the distance between metropolitan areas to migrate. In a second step we use the results of this statistical model to simulate, in an agent-based model, migrants' decision to move to different destinations. We do this process using two different definitions of the statistical model. First we model the effect of amenities explicitly (model A). In a second model (model B), we model amenities implicitly, á la Glaser, and include measures of the distance between metropolitan areas. We describe this modeling approach in detail in this section.

Similar to other studies that consider agents that represent real people living in actual regional landscapes (Widener et al., 2013; Benenson et al., 2003), the simulations used in this study works with 2,035 individuals that represent actual intermetropolitan migrants in the 2010 Population Census (INEGI). An internal migrant is defined as an individual that 5 years ago lived in another metropolitan area. To choose these individuals, we selected a $1 \%$ random sample of the intermetropolitan migrants in the census survey. ${ }^{10}$ Therefore, they represent real individuals over 18 years old with specific own-individual characteristics such as sex, education and age. The distribution of the internal migrants across metropolitan areas of this random sample reproduces, in the initial condition of the simulation, the actual distribution of intermetropolitan migrants provided in the census (see table 1). Likewise, the simulation works with the 56 metropolitan areas of Mexico (according to CONAPO's 2007 classification $^{11}$ ) that are incorporated into the simulation through a point shape file that represents a true cartography of these cities (see figure 6). This means that the distances and spatial location of the results are accurate. Economic and demographic data attributed to each metropolitan area come from the industrial census (INEGI, 2008), the population census (INEGI, 2010) and other sources.

This model operates in two steps. First we estimate for each individual, in each metropolitan area, the probability that it stays in that area (0) or that it migrates to another metropolitan area (1). This probability is estimated using a type of dynamic logit model that is a function of both individual characteristics and of the place where the individual is living:

$$
\operatorname{Pr}(\Omega(\mathrm{t}+1)=[1])=\frac{\exp \left[\mathrm{X}_{\mathrm{t}} \beta+\mathrm{Z}_{\mathrm{t}} \lambda\right]}{1+\exp \left[\mathrm{X}_{\mathrm{t}} \beta+\mathrm{Z}_{\mathrm{t}} \lambda\right]}
$$

10 As the census includes the question of internal migration in its long questionnaire, this means that these come from a $0.01 \%$ sample of the Mexican population.

11 There were only 56 metropolitan areas in México in 2005. In order to be classified as a metropolitan area, a city needs to comply with certain size, economic organization and regional dominance criteria (Conapo 2007). 
where $\Omega$ is a vector of intermetropolitan migrants (i's) that live in the metropolitan area $\mathrm{j}, \mathrm{X}$ is a vector of individual characteristic of these migrants such as sex, education and age; $\mathrm{Z}$ is a vector of contextual or urban economic characteristics of each metropolitan area, associated with economic variables (wages, industry and service employment rates), amenity endowments (such as restaurants, hotels, entertainment sites, etc.), and urban hierarchy (proximity to other metropolitan areas).

To implement the migration decision rule just mentioned above (whether or not to migrate), we assign a generated random number between 0 and 1 to each individual. If this number is greater than the probability that the individual got from equation (1), it moves to another metropolitan area, otherwise it stays in its current place of residence. ${ }^{12}$ With this we have the simulated emigrants from each metropolitan area at time t.

Once we have these emigrants, in a second step we model how they distribute across destinations. Each migrant can choose across 55 different destinations. To make these destination decisions, the model functions based on rules of connectivity across metropolitan areas that vary randomly from one metropolitan area to another, and from one simulation trial to the next. These rules are supposed to emulate how migrants make decisions based on the knowledge they have about potential destinations. In them, a migrant in metropolitan area $j$ is connected through an information network with a random number of other metropolitan areas (which we call neighbors). The number and identity of the neighbors of each metropolitan area in each simulation exercise is random, but we control the mean number of neighbors by the set of the metropolitan areas (or the average MA degree). The network structure of each metropolitan area (which other metropolitan areas they are connected to) is based on proximity between cities (given by euclidean distance). The specific rule to create the network structure is through connecting metropolitan areas by (closest) links, that is, it is a simple graph that does not have loops (self-links) and does not have multiple identical links. The number of metropolitan links is calculated standardly as follows:

Number of metropolitan links $=\left(\right.$ average-MA-degree $\left.{ }^{\star} 56\right) / 2$

where average-MA-degree is a parameter that takes a number in the range $[0,55]$ and 56 accounts for the total nodes or metropolitan areas in Mexico. The average-MA-degree is the same for each agent but the links that connect specific metropolitan areas for each agent tend to be slightly different along the range $[0,55]$. 

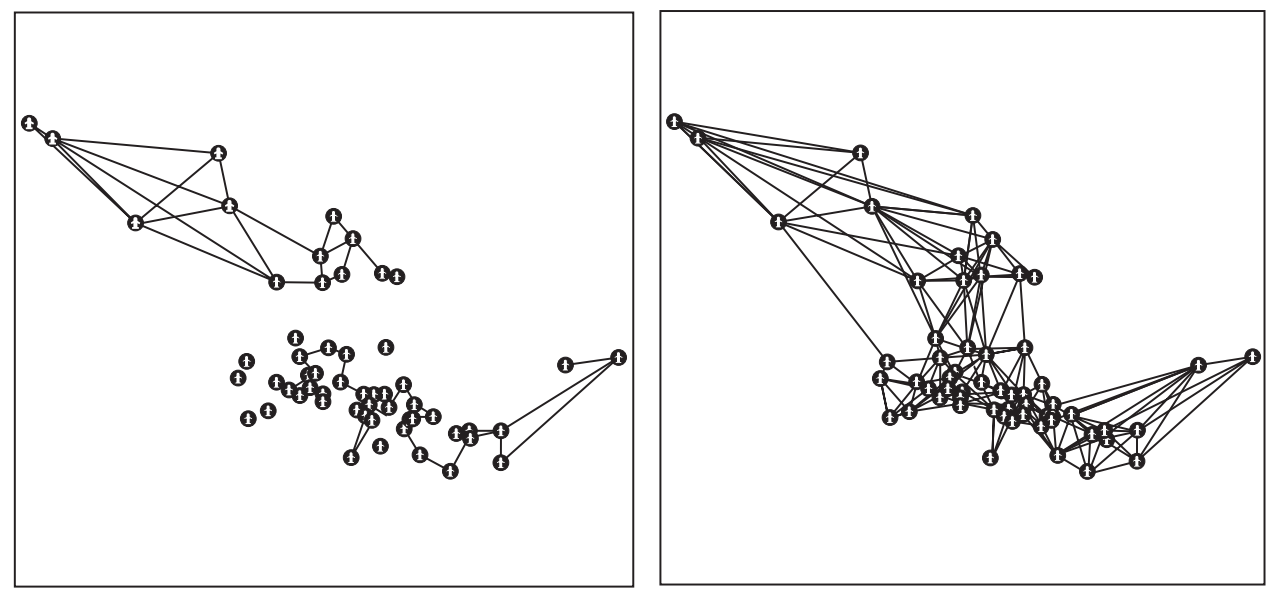

To construct the network, a metropolitan area is randomly chosen and connected to the nearest metropolitan areas that it is not already connected to. This process is repeated until the network has the correct number of links to give the specific average number of neighbors. To illustrate the structure of these networks, figure 6 displays two random networks. The one on the left has an average number of neighbors of 3, while the one on the right has an average number of networks of 10 .

In the case that a metropolitan area is not assigned with a neighbor (for example, this could happen when the average node degree is too low), the individuals who live there will be provided with information of other metropolitan areas according to an Euclidean distance $\mathrm{R}$ that is controlled by a parameter in the simulation model. $\mathrm{R}$ represents a radius for each metropolitan area and all metropolitan areas that are inside of such radius will be allowed to be accessed by the individual. In these cases, the average number of neighbors is 37.

To decide to which metropolitan area to move to, individuals calculate, for each of the metropolitan areas in their network, a probability of moving there. This probability is based on the results on the equation (1) for that metropolitan area. These probabilities will allow to compare migrants the benefits that they would be obtaining from moving across their different potential destinations, given the expected wages and amenities there, as well as their own characteristics. Following this logic, migrants move to the metropolitan area where they obtained the highest estimated probability. In order to generate computational statistics, each simulation is run at least 20 times for each set of parameters used; and the simulations are run 
again after a warmth period in where the system reaches a steady equilibrium. The simulations presented in the next section in general start from an average MA degree network of 1 and end with an average of 55 neighbors for a specific set of parameters to calculate migrant probabilities.

The descriptive statistics of agents and metropolitan areas are depicted in table 1

TABLE 1. Descriptive statistics of variables used in the model

\begin{tabular}{|c|c|c|c|c|c|}
\hline & Obs. & Mean & Std. Dev. & Min. & Max. \\
\hline Total internal migrants & 2035 & - & - & - & - \\
\hline Male & 1065 & - & - & - & - \\
\hline Female & 970 & - & - & - & $\longrightarrow$ \\
\hline Age & - & 32.1 & 11.6 & 15 & 65 \\
\hline Years of schooling & $\longrightarrow$ & 10.3 & 4.2 & 0 & 23 \\
\hline \multicolumn{6}{|l|}{ Contextual variables } \\
\hline Museums per capita & 56 & $8.7 \mathrm{E}-06$ & $6.6 \mathrm{E}-06$ & $0.0 \mathrm{E}+00$ & $2.6 \mathrm{E}-05$ \\
\hline Cultural facilities per capita & 56 & $3.1 \mathrm{E}-05$ & $2.4 \mathrm{E}-05$ & $0.0 \mathrm{E}+00$ & $1.1 \mathrm{E}-04$ \\
\hline Hotels per capita & 56 & $2.2 \mathrm{E}-04$ & $1.5 \mathrm{E}-04$ & $4.4 \mathrm{E}-05$ & $8.4 \mathrm{E}-04$ \\
\hline Restaurants per capita & 56 & $4.6 \mathrm{E}-03$ & $1.4 \mathrm{E}-03$ & $2.6 \mathrm{E}-03$ & $8.4 \mathrm{E}-03$ \\
\hline Hospital per capita & 56 & $9.9 \mathrm{E}-05$ & $3.1 \mathrm{E}-05$ & $5.3 \mathrm{E}-05$ & $1.9 \mathrm{E}-04$ \\
\hline Health care \& social assit. facilities & 56 & $2.4 \mathrm{E}-05$ & $1.4 \mathrm{E}-05$ & $0.0 \mathrm{E}+00$ & $7.6 \mathrm{E}-05$ \\
\hline Entertainment facilities per capita & 56 & $5.0 \mathrm{E}-04$ & $2.1 \mathrm{E}-04$ & $2.0 \mathrm{E}-04$ & $1.3 \mathrm{E}-03$ \\
\hline Wage in service sector & 56 & 26.8 & 8.4 & 12.1 & 45.8 \\
\hline Expected wage $(2003=100)$ & 56 & 7.0 & 4.7 & 1.3 & 19.6 \\
\hline Price new housing $\mathrm{m}^{2}$ & 56 & 4034.3 & 1079.9 & 2289.7 & 7385.9 \\
\hline \multicolumn{6}{|l|}{ Gross Value Added Product } \\
\hline per capita & 56 & 40.6 & 28.2 & 6.9 & 177.2 \\
\hline Distance $\mathrm{km}$ to MA with 500 & & & & & \\
\hline $\begin{array}{l}\text { thousand inhab. } \\
473.5\end{array}$ & 56 & 141.7 & 83.3 & 28.7 & \\
\hline Distance $\mathrm{km}$. to MA with 1,000 & & & & & \\
\hline
\end{tabular}




\section{Simulation results}

In this section, we present results based on simulations applying the model proposed in section 3 to analyze the dynamics of internal migration among metropolitan areas in Mexico. In order to restrict the parameter space associated with the variables in the simulations, we rely on a typical logit estimation of equation (1) but without subscripts.

Table 2 displays two different model specifications used in the simulations and their logit estimations (equation 1) using census data 2010. The factors used in these models, consist of variables that denote migrants' socioeconomic characteristics,

TABLE 2. Parameters estimated by the logit model that are used in the simulations (results of equation 1)

\begin{tabular}{|c|c|c|c|c|c|c|}
\hline & \multicolumn{3}{|c|}{ Model A } & \multicolumn{3}{|c|}{ Model B } \\
\hline & Coef. & $\begin{array}{l}\text { Std. } \\
\text { Err. }\end{array}$ & $\mathrm{z}$ & Coef. & $\begin{array}{l}\text { Std. } \\
\text { Err. }\end{array}$ & $\mathrm{z}$ \\
\hline Years of schooling & 0.037 & 0.006 & 6.28 & 0.038 & 0.006 & 6.49 \\
\hline Age & -0.017 & 0.002 & -9.11 & -0.017 & 0.002 & -9.1 \\
\hline Cultural facilities per capita & 3862 & 1485 & 2.6 & & $\longrightarrow$ & - \\
\hline Hotels per capita & 743 & 312 & 2.39 & & - & - \\
\hline Restaurants per capita & 67 & 39 & 1.7 & & - & - \\
\hline Hospitals per capita & -6360 & 1289 & -4.93 & - & - & - \\
\hline Health care \& social assit. facilities & & & & & & \\
\hline per capita & 7820 & 2535 & 3.09 & & & \\
\hline Enterteinment facilities per capita & -540 & 278 & -1.94 & - & - & - \\
\hline Expected wage $(2003=100)$ & 0.056 & 0.008 & 6.74 & 0.026 & 0.007 & 3.65 \\
\hline Wage in service sector & -0.030 & 0.004 & -7.58 & -0.027 & 0.004 & -6.02 \\
\hline Amenity premium (residuals) 2008 & - & - & - & 0.076 & 0.031 & 2.47 \\
\hline Distance $\mathrm{km}$ to MA with 500 & & & & & & \\
\hline thousand inhab. & - & - & - & -0.001 & 0.000 & -2.42 \\
\hline Distance $\mathrm{km}$ to MA with 1,000 & & & & & & \\
\hline thousand inhab. & - & - & - & 0.001 & 0.000 & 5.55 \\
\hline Constant & -1.629 & 0.230 & -7.08 & -1.662 & 0.129 & -12.89 \\
\hline
\end{tabular}


variables that are meant to describe the economic conditions in the destination area, and variables that are intended to represent the amenities in the destination area. The choice of variables in each model simulation was made based on the results of the logit models (only those variables that were significant at the $0.05 \%$ level were included). We implemented two models, which vary on the way that they approach the measurement of amenities. With the exception of this aspect and two indicators of distance that are only incorporated in the model B, the two models include the same variables. To represent migrants' characteristics, we use years of schooling and age, while we use expected average wage and wage in the service sector as contextual economic variables. In table 2, we present the specification of Model A, which includes the following set of variables that measure amenities in the place of destination directly: the number of museums, hotels, athletic and cultural facilities, restaurants, hospitals, health care and social assistance facilities, and entertainment facilities per capita.

In table 2 we present the specification of model $\mathrm{B}$, which measures amenities indirectly (see amenity premium variable). In this model, we drop the amenities variables and we calculate the amenity effect indirectly only as a regression residual. This methodological approach to measure amenities was proposed by Glaeser et al., (2001). In this application, we first regress average new house prices on Gross Value Added Product per capita in each metropolitan area in 2008. The standardized residuals of this regression are used as the indicator of amenities. In model B we also included two variables associated to urban hierarchy in the region: the distance to the nearest metropolitan area with more than 500,000 inhabitants and the distance to the nearest metropolitan area with more than 1,000,000 inhabitants.

As we explained before, an important characteristic of the simulations is that they allow us to restrict the flow of internal migration across metropolitan areas. The assumption here is that individuals in one metropolitan area will only migrate to the metropolitan areas they know about. This assumption is implemented through a random network interaction between metropolitan areas (see equation 2). As we detailed in the last section, in this network metropolitan areas are connected randomly with some other metropolitan areas (that we call "neighbors"), but not with others. The average number of neighbors or average-MA-degree is controlled by a parameter in each of the simulations. We start with an average of one neighbor per metropolitan area (that is, each metropolitan area is connected only to another metropolitan area), and then this value is systematically increased until each metropolitan area is almost connected with the others (what we call "a full neighbor interaction"). This full neighbor interaction means that each metropolitan area has 56 neighbors. In each simulation, the metropolitan areas that are connected in the network (what can be named the network interaction) are randomly assigned, but 
always the nearest metropolitan area will be assigned first as a neighbor. When a metropolitan area does not have a neighbor, potential migrants have access to the information of all metropolitan areas that are inside a radius of 10 (in netlogo distance, which is the computational programing used in this research), which is equivalent to an average of 37 neighbors for each metropolitan area. The assumption in this programming decision is that instead of having a concentrated migration flow, cities that do not have a clear network have more disperse migration flows.

Figure 7 displays the results of model A under the effects of different network structures of interaction among MAs. On the $\mathrm{x}$-axis is the neighbor-interaction structure or average-MA-degree of each simulation, while the $y$-axis shows the share of internal migrants. After defining the network conditions (an average of no neighbors -observed-, an average of one initial neighbor, etc. ${ }^{13}$ ), each simulation is run 20 times. Each time a simulation is run, we let it run 20 times, disregarding the first 10 results as the warming period ${ }^{14}$ and averaging the last 10 results to have a general result of the each simulation. Since each simulation is run 20 times, we repeat the process of averaging the last 10 results for each initial condition 20 times. After doing this, we averaged these 20 results, and obtained a global result for each of the original conditions. This is what is shown in each of the points in the y-axis of figure $1 .{ }^{15}$

The figure 7 shows only the metropolitan areas with higher shares of internal migration. To decide which metropolitan areas are shown in each simulation, we did the following: Guadalajara, Monterrey, and Valle de Mexico always appear as the three most important destinations. We always show these areas. In addition, we select, in each simulation, the two metropolitan areas that are emerging as important places of destination in addition to Guadalajara, Monterrey and Mexico City.

Model A's main result is that the way that migrants distribute across different metropolitan areas depends on the information that migrants have on their potential destinations. As depicted in figure 7, this dynamic makes migrants choose among destinations that are economically non-optimal and distribute among more places, when they have bounded information, and leads them to concentrate in the destinations that are economically optimal once they have information about all their potential destinations. To make these ideas clearer, in this model A Monterrey is the metropolitan area that offers the best economic conditions and amenities. To see what happens when migrants have bounded information about their potential

\footnotetext{
13 The label "observed" in the $\mathrm{x}$-axis in the graph refers to the actual migration.

14 The results of the first rounds of each simulation are always very unstable and are usually not considered.

15 Consequently, the results in figure 7 are an average of averages.
} 
destinations, ${ }^{16}$ focus on the space in figure 7 that covers the values in the $\mathrm{x}$-axis between neighbors 3 and 30. These values represent the evolution of an average number of neighbors in the network from 3 to 30 , while the y axis shows the share of migrants in different responses by migrants to these changes. What is important to notice in this interval is that migrants distribute among several destinations, with no clear dominance of Monterrey. For example, in the range of 2 to 4 neighbors the three main destinations are Valle de Mexico, Toluca and Monterrey. In the range of 5 to 7 neighbors, there are two dominant destinations: Valle de Mexico and Toluca, while in the interval of 9 to 20 neighbors Oaxaca emerges as the main destination, followed by Tehuacan. ${ }^{17}$

FIGURE 7. Network effects on the simulation using the results of model A

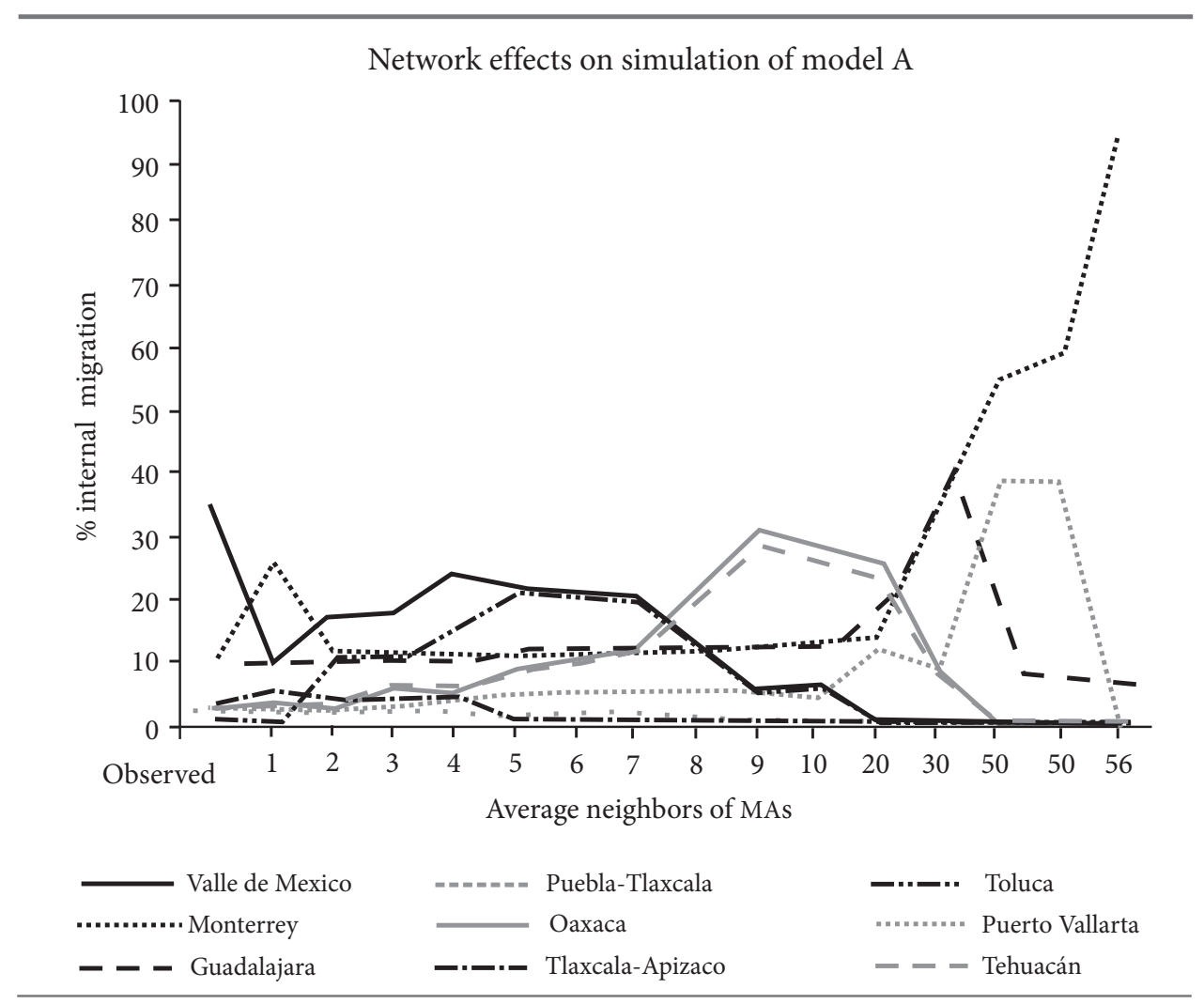

16 That is, they only know about a limited number of potential destinations because the average number of neighbors in the network is much lower than the total number of metropolitan areas. 
As individuals have information about more destinations (i.e., the average number neighbors in the network increases and we move to the right of figure 7), migrants tend to concentrate in a fewer number of destinations. This effect is clearly appreciated from neighbors 8 onwards, where a few cities concentrate $30 \%$ of the migrants and more. When metropolitan areas have an average of 40 neighbors, Monterrey starts to dominate as the main area of destination. At the right end of figure 7, when there is a full information network (that is, every metropolitan area is connected), this city is definitely the main place of destination. This result is explained, in this model, because Monterrey has the best economic conditions and amenities. Once potential migrants can compare this metropolitan area with all the others, they would be making an "economically-rational decision" and migrate to Monterrey.

Another result that is important to analyze in this model $\mathrm{A}$ is the behavior of the share of internal migrants that the Valle de Mexico metropolitan area receives as the average number of neighbors in the network increases. The observed migration share of this metropolitan area is $36 \%$. When the average number of neighbors in the network is 1, under this model, this metropolitan area would only be receiving about $10 \%$ of urban migrants. What happens in this case is that other metropolitan areas of the central region like Tula, Toluca and Cuernavaca are the main destinations of the emigration from both Mexico City and from the metropolitan areas from the center of the country, which is the most populated one. When the average number of neighbors in the network is between 2 and 7, the relevance of the Valle de Mexico as a destination rises to reach of level between $20 \%$ and $25 \%$. After the average number of neighbors in the network reach 8, the share of migrants in the Valle de Mexico metropolitan area decreases steadily.

Putting all these results together, one can see that, within all the range of average neighbors per network showed in figure 7 the central values are the ones that make most sense. Although not exact, these reflect both the continued presence of the Valle de Mexico metropolitan area as an important destination, and the diversification of destinations of urban migrants in Mexico -something that has been documented in the empirical literature before (Sobrino, 2010). Theoretically, the medium specter of the distribution in this figure is also the most reasonable one. It is unrealistic to assume that individuals only know about one or two metropolitan areas, especially as these are urban migrants that may be more informed and educated than migrants from rural areas. The assumption at the right-extreme of

country, and thus they attract the population of high-density metropolitan areas such as Mexico City. In particular, Oaxaca is attractive because it has many amenities related to its historical heritage. Something similar happens with Puerto Vallarta. This port, located in the north pacific, emerges as an important place of destination later in the figure, when the number of neighbors increases. 
figure 7 (that individuals have full information about) is equally unfeasible. Nevertheless, we show the results in the whole range of average number of neighbors per network to give an idea of what would happen as the information about possible destinations evolves.

Why do the results of this model not coincide with the observed migration patterns (labeled "observed" in figure 7)? There may be two possible explanations. One is that the dominance of the Valle de Mexico observed in the internal migration patterns may still carry inertia from past decades, which can be reflecting, among other things, the role of social networks which are not included in this model. A second explanation is that in this model neighbors (and thus information about potential destinations) are assigned randomly. However, this is not necessarily the case. Both migration theory and past research suggest that the information that individuals obtain from potential destinations depend on their migration networks, the relative importance of the metropolitan areas in the regional and national context, economic links between states, and transportation networks (Rivero, 2012). Taking this into account, the continued predominance of the Valle de Mexico can be

FIGURE 8. Network effects on simulation using the results of model B

Network effects on simulation of model B

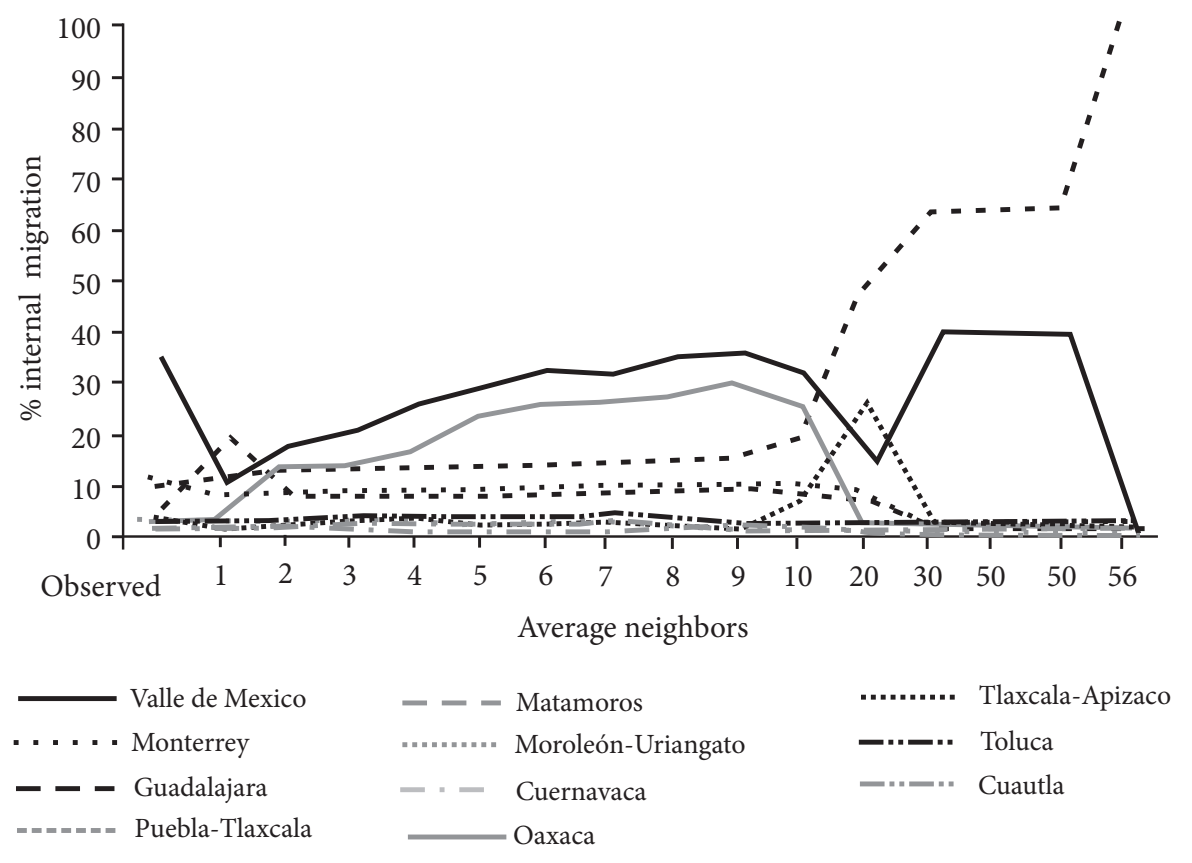


explained through both past networks and its national importance in the media. Albeit these limitations, the results of this simulation show what would happen as information becomes more available (see figure 7, from neighbors 2 to 8 ). These results do not only make sense, but coincide with what has been happening in the last twenty years in Mexico (Rivero, 2011; Sobrino, 2011): Migrants' destinations have been diversifying, as they learn about other places.

We repeated the same simulation exercise we did with model A, with model B. Figure 8 shows these results. Guadalajara is the metropolitan area with the best amenities conditions as measured indirectly according to the methodology implemented in this model and explained above (see variables in table 2). This implies that the amenities in a metropolitan area go beyond museums, health centers, schools, and the other variables included in model A. Before explaining the results of this model further, it is important to remind the readers that this model differs from model A in two aspects: 1) in the way it measures amenities, and 2) in that this model includes a measurement of distance. ${ }^{18}$

The results of model $\mathrm{B}$ mimic those of model $\mathrm{A}$ in the sense that the distribution of migrants across different metropolitan areas depends on the information that migrants have about their potential destinations. In this model, however, this effect is mediated by the effect of distance, which helps to explain the dominance of the metropolitan areas of Valle de Mexico and Cuautla when migrants have incomplete information. When there are between 2 and 9 average neighbors per network, the share of migrants in different metropolitan areas does not surpass $35 \%$, and migrants distribute among several locations. One of the relevant results in this model is that in this interval the metropolitan area of Valle de Mexico is the main destination of urban migrants. Based on the simulation results we estimate that when there is an average of 6 to 10 neighbors per network, this area would receive approximately $35 \%$ of the share of urban migrants. The results in this interval are very similar to the observed, except for the high share of migration that is simulated for Cuautla. There are not strong economic or amenity elements to suppose that this metropolitan area has an advantage to attract high numbers of migrants. Nevertheless, this result suggests that when local interaction and distance prevail to restrict migration flows (mainly in the central region of Mexico), the metropolitan area of Valle de Mexico cannot absorb all migration flows and then it is likely that

Hence, the differences in the results can be attributable to either one of these aspects. In addition to running model $\mathrm{B}$, we ran a model that differed from model A only in the way that the amenities variables were implemented. The results of this model differed both from model A and from model B, but we do not present them here for easiness of exposition (results are available upon request) in the following fashion: as information increases, instead of the metropolitan area of the Valle de Mexico, Monterrey is the second most important destination. 
another metropolitan destination close to this city emerges as an important place of attraction. ${ }^{19}$ Additionally, this alternative migration destination would be serving as the principal destination of the migrants from the metropolitan area of Valle de Mexico. As the information that migrants have about potential destinations increases (i.e., the average number of neighbors per network rises), Guadalajara emerges as the main region of migration. This metropolitan area, located in the north occidental part of the country, is the second largest city in the country and is geographically closer to all the cities in the meridional part of the country, as well as in the northern region.

So far, we have restricted the parameter value of the variables used in the simulations to the ones estimated by the logit procedure (see table 2). Next, we evaluate the effect of an increasing effect of the parameter associated to amenities on FIGURE 9. Amenity effect on internal migration. Average neighbors 1

Amenity effect on internal migration. Network

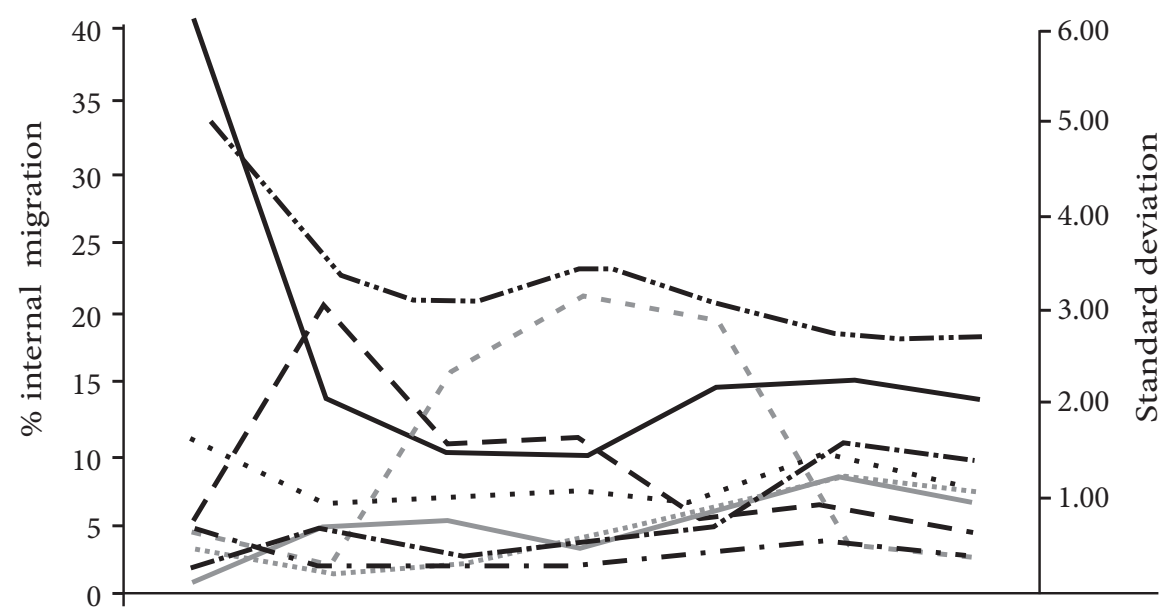

Observed Amen. Amen. 1 Amen. 5 Amen. 10 Amen. 50 Amen. 100 0.075

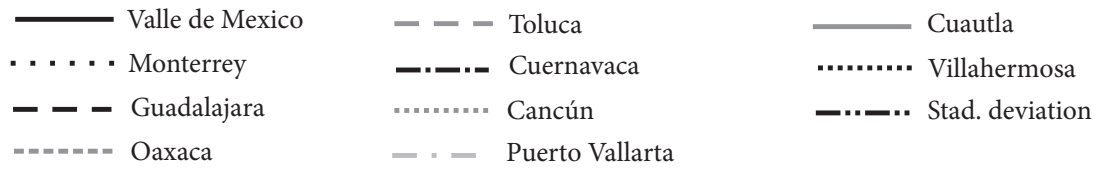

19 Note that in model A this alternative destination is Toluca. 
the dynamics of internal migration share. To see this, we concentrate in simulating Model B. Figure 9 depicts the equilibrium outcome under the conditions when neighbors are in average 1 and it is analyzed the effect of an increasing amenity parameter starting from the one estimated by logit (0.075). The figure also displays the standard deviation series (see curve in black) whose values are referred on the secondary y-axes (see right axes). We recall that when the simulation has in average 1 neighbor, there are - in each run - some metropolitan areas that do not have link-neighbors, in these cases, migrants are provided with information that covers in average 37-nearest metropolitan areas. As it happens also in figure 8, in figure 9 amenity 0.075 makes Guadalajara the most important destination with $20 \%$ share —and this is expected because most migrants have access to the "optimal" targetNevertheless, Guadalajara loses attraction with greater amenity effect (for example, at amenity 1, Guadalajara falls to 10\%). A main result in the figure 9 is the convergence outcome when the amenity parameter increases; note that at amenity 50 and 100, all mayor destinations have migration shares less than $10 \%$. This result would be consistent with what the spatial equilibrium approach predicts (see section 1), that is, amenities are capitalizing regional differences in prices making internal migrations rates more o less equal. This process of convergence is also reflected in the diminishing series of the standard deviations of the internal migration share (see black series). Figure 9 shows in general which metropolitan areas emerge like winners in a scenario where amenities are driven the migration decisions. In particular, Puerto Vallarta with a share close to $20 \%$ emerges as the main destination in the range of amenities 5-10; likewise, Cuernavaca - a metropolitan area very close to Mexico City - reaches levels of migrations share of $10 \%$ when amenity effect is 50; also MAs like Oaxaca y Cancun tend to increase its migration share with increasing amenity effect but with a lower intensity. What is common in these last MAs is that they are mayor touristic destinations, either national or international, in the country. Puerto Vallarta emerges as the main migration destination in the simulation - in some range of amenity effects - because of its proximity with Guadalajara which is the equilibrium outcome of the model under full information.

Finally, in figure 10 is simulated the model B but now when the average number of neighbors is 5 . Under this scenario is observed also a process of convergence in the internal migration share (see the standard deviation series in black), but Mexico City persist as the mayor internal destination even when this has a decreasing tendency with increasing amenity effect; for example, note that Mexico City has around of $18 \%$ of internal share when amenity is equal to 100 . Toluca - which is the closest MA to Mexico City with greater level of industrialization- emerges as the second internal migration destination when amenity effect is in the range 1-50 with internal share levels that reach above $20 \%$ (see amenity 1 and 5). The other two mayor 
Amenity effect on internal migration. Network

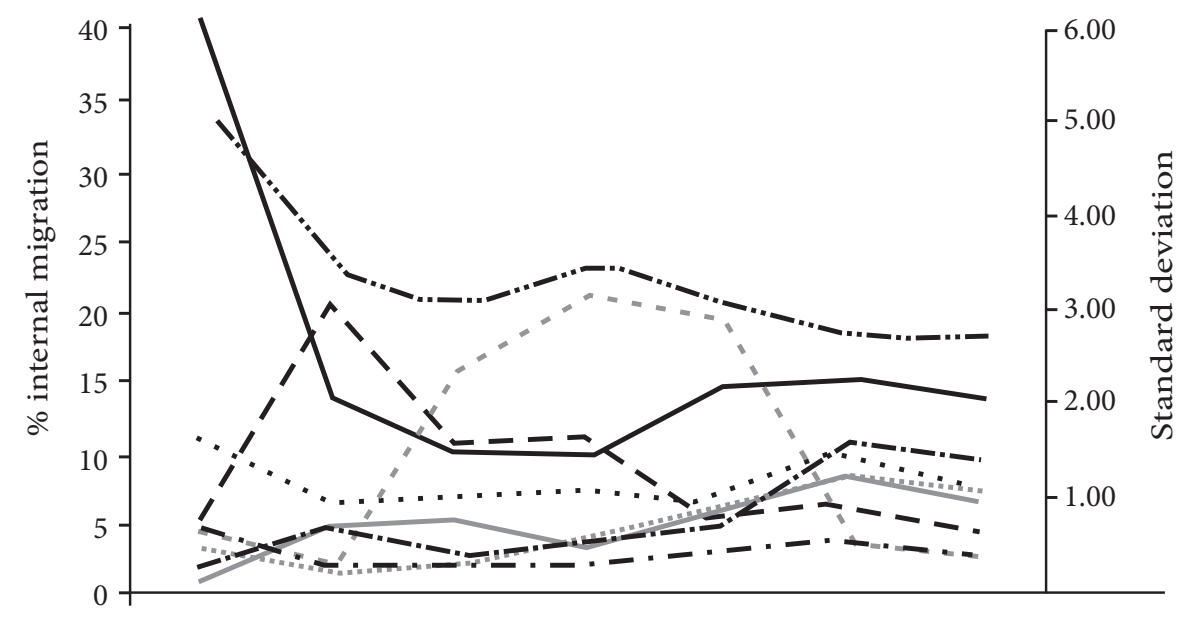

Observed Amen. Amen. 1 Amen. 5 Amen. 10 Amen. 50 Amen. 100 0.075

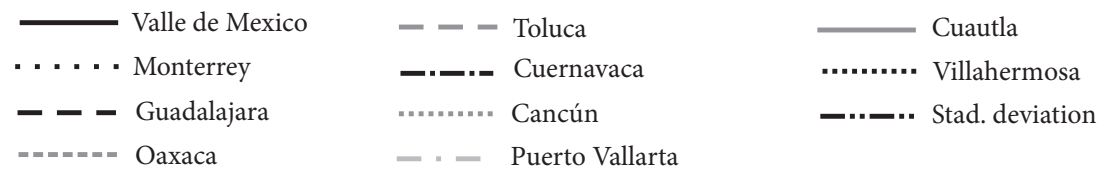

internal migrations destinations in the country (Monterrey and Guadalajara) remain steady along the figure. At amenity 0.075 , Cuautla -which is also a MA close to Mexico City- emerges as the second destination but then drops drastically when amenity increases to 1 . Cuernavaca compete with Toluca when amenity is 50 or 100, and Cuautla emerges again as important destination with amenity 100 . The main characteristic of Cuernavaca or Cuautla is that they are important weekend destinations for people living in Mexico City. In general, under this simulation in where there is a relatively high local level of interaction (5 neighbors), Mexico City continues being an important final destination in the country but with a diminishing presence if the amenity effect increases; in this sense, it seems that the main winner of an increasing amenity effect would be Toluca. Local interaction with strong effect of amenities tends to contain the flow of migration from the center toward the north metropolitan areas (such as Guadalajara o Puerto Vallarta). 


\section{Concluding remarks}

In this paper we analyzed the dynamics of intermetropolitan migration in Mexico through a spatial computational hybrid model. This model is called "hybrid" because it integrates GIS and agent based simulation elements to analyze intermetropolitan migration dynamics at the individual level. ${ }^{20}$ In doing this, we simulate migration decision-making behavior of "artificial agents" that represent -in location and demographics - real people of the Mexican census data 2010. This approach has a geographic and contextual binding force in agents that make migration-decision behavior modeling a little closer to real life environments than commonly used in econometrics. Two of the advantages of the simulations are that they allowed us to identify which of the factors that we introduced in our exercise are the most influential, and that they allowed the generation of dynamic scenarios of intermetropolitan migration in the near future.

Some simulations results are consistent with a decline in the concentration of the intermetropolitan migration flows, which also suggests a diversification of destinations that Mexico has registered in recent decades. This conclusion emerges from the fact that in our simulations amenities are an important attracting force to specific metropolitan areas -an issue little explored in migration studies for Mexico. When this result is played dynamically in our simulations, these suggest that if amenities were to increase its potential, touristic destinations that are close to large metropolitan areas would increase their power of attraction for internal migrants. In particular, Puerto Vallarta, Oaxaca and Cancun may become important internal migration destinations.

An important feature of the methodological approach adopted here is that it allowed to introduce a type of bounded rationality in agents, in the sense that in order to make their migratory decisions they were only able to have local information from the closest network-metropolitan areas. This assumption is crucial to replicate the observed internal migration shares across metropolitan areas, which implies that local interaction between metropolitan areas is key in shaping intermetropolitan migration. This implies that that internal migration decisions may be restricted to the knowledge that the inhabitants from metropolitan areas gather from no more than a small group of local neighbors, where interactions are conditioned by proximity to urban hierarchy. This is particularly true for the large size metropolitan areas like Mexico City, which restricts the flow of migrants from the central region of Mexico.

In terms of theoretical implications, the computational simulations would suggest that the actual decline in the rate of internal migration across metropolitan

For a detailed discussion about hybrid agent-based approaches see Birkin and Wu (2012). 
areas does not necessarily imply a spatial equilibrium scenario as the General Spatial Equilibrium framework would indicate. On the contrary, because local interaction factors play a crucial role in the dynamics of intermetropolitan migration, it is not possible that migrants were equalizing their utility indexes across metropolitan areas.

Finally, it is important to mention the potential of relying on the computational modeling framework adopted here and the possibilities of further developments. The model analyzed here is quite simple because even when it is constrained by geographic and contextual factors due to the integration with GIS, it models migrant decisions in scenarios were many other influential factors are given or determined exogenously. If we would rely on a spatial equilibrium framework, one option of further models is to consider also locational decisions of firms and developers' choices to construct housing, and along with migrants' choices, to determine endogenously wages, housing prices and metropolitan areas' size. Future research must address this and other theoretical approximations.

\section{References}

Benenson, I., Omer, I., \& Erez, H. (2003). Agent-based modeling of householders' migration behavior and its consequences. In Billari, F., \& Prskawetz, A. (eds.), Agent-based computational demography. Heidelberg, New York: Physica-Verlag.

Birkin, M., \& Wu, B. (2012). A review of microsimulation and hybrid agent-based approaches. In Heppenstall, A., Crooks, A., See, L. \& Batty M. (eds.). Agent based models of geographical systems (pp.51-68). Dordrecht: Springer.

Borjas, G. (2000). Economics of migration. In International Encyclopedia of the Social and Behavioral Sciences, section 3.4, article 38.

Brackman, S., Garretsen, H., \& Marrewijk, C. (2009). The new introduction to geographical economics. United Kingdom: Cambridge University Press.

Caballero, R. J., \& Lyons, R. K. (1992). The case for external economies. In Cukierman, A., Hercowitz, Z., \& Leiderman, L. (eds.), Political economy, growth, and business cycles (pp. 117-139). Cambridge, MA: MIT Press.

Chan, V.-L., Chen, B.-L., \& Cheung, K.-N. (1995). External economies in Taiwan's manufacturing industries. Contemporary Economic Policy, 13, 118-130.

Consejo Nacional de Población (Conapo), Secretaría de Desarrollo Social (Sedesol) \& Instituto Nacional Estadística, Geografía e Informática (INEGI) (2007). Delimitación de zonas metropolitanas de México 2005. México: Conapo, Sedesol, INEGI.

Crozet, M. (2004). Do migrants follow market potentials? An estimation of a new economic 
geographic model. Journal of Economic Geography, 4(4), 439-458.

Evans, A. W. (1990). The assumption of equilibrium in the analysis of migration and interregional differences: a review of some recent research. Journal of Regional Science, 30(4), 515-531.

Florida, R. (2005). Cities and the creative class. London: Routledge.

Florida, R. (2003). The rise of the creative class. New York: Basic Books.

Glaeser, E. L., \& Gottlieb, J. D. (2009). The wealth of cities: agglomeration economies and spatial equilibrium in the United States. National Bureau of Economic Research.

Glaeser. E. (2008). Cities, agglomeration and spatial equilibrium, Oxford: Oxford University Press.

Glaeser, E., Kolko, J., \& Saiz, A. (2001). Consumer city. Journal of Economic Geography, 1.

Graves. P. E. (1976). A reexamination of migration, economic opportunity and the quality of life. Journal of Regional Science, 16.

Greenwood, M. J. (1985). Human migration: theory, models, and empirical studies. Journal of regional Science, 25(4), 521-544.

Instituto Nacional Estadística y Geografía (INEGI) (2000). XII Censo General de Población y Vivienda 2000. Aguascalientes: INEGI.

Instituto Nacional Estadística y Geografía (INEGI) (2005). II Conteo de Población y Vivienda 2005. Aguascalientes: INEGI.

Instituto Nacional Estadística y Geografía (INEGI) (2010). Censo de Población y Vivienda 2010. Aguascalientes: INEGI.

Instituto Nacional Estadística y Geografía (INEGI) (200). XVII Censo Industrial 2009. Aguascalientes: INEGI.

Kniveton, D., Smith, C., \& Black, R. (2012). Emerging migration flows in a changing climate in Dryland Africa. Nature Climate Change, 2(6), 444-447.

Krugman, P. (1991). Increasing returns and economic geography. The Journal of Political Economy, 99(3).

Noriega Vera, J. A. (2007). Condiciones psicosociales de los niños y sus familias migrantes en los campos agrícolas del noroeste de México. Revista Intercontinental de Psicología y Educación, 9(1).

Partida, V. (2013). Migración hacia y desde 16 zonas metropolitanas de México. Una reconstrucción histórica 1965-2010. Papeles de Población, 76, 9-51.

Partrigde, M. D. (2010). The duelling models: NEG vs amenity migration in explaining US engines of growth. Papers in Regional Science, 89(3).

Partridge, M. D., \& Rickman, D. S. (1997). The dispersion of US state unemployment rates: the role of market and non-market equilibrium factors. Regional Studies, 31(6), 593606. 
Partridge, M. D., Rickman, D. S., Olfert, M. R., \& Ali, K. (2012). Dwindling U.S. internal migration: evidence of spatial equilibrium or structural shifts in local labor markets? Regional Science and Urban Economics, 42, 375-388.

Pérez, E., \& Santos. C. (2013). Tendencias recientes de la migración interna en México. Papeles de Población, 19(76), 53-88.

Rivero, E. (2012). Beyond income differentials: explaining migrants'destinations in Mexico. In Cuecuecha, A., \& Pederzini, C. (eds.), Migration and remittances from Mexico, trends impacts and new challenges. Mexico: Lexington.

Roback, J. (1982). Wages, rents and the quality oflife. Journal of Political Economy, 90(4).

Rosen, S. (1979). Wage-based indexes of urban quality of life. In Mieszkowski, P., \& Straszheim, M. (eds.), Current issues in urban economics. Baltimore: Johns Hopkins University Press.

Segoura, I. (1998). Return to scale and external economies: empirical evidence from Greek two-digit manufacturing industries. Applied Economic Letters, 5, 485-490.

Sobrino, J. (2007, April 17). Migración interurbana en México. In Taller Nacional sobre Migración Interna y Desarrollo en México: Diagnóstico, Perspectiva y Políticas. Mexico: ECLAC, IDB.

Sobrino, J. (2010). Migración urbana. In Conapo, La situación demográfica de México, 2010 (pp. 155-170). México: Conapo.

Sobrino, J. (2010). Migración interna en México durante el siglo XX. México: Conapo.

Sjaastad, L. A. (1962). The costs and returns of human migration. The Journal of Political Economy, 70(5).

Stark, O., \& Levhari, D. (1982). On migration and risk in LDCs. Economic Development and Cultural Change, 31(1), 191-196.

Stoper, M. (2013). Keys to the cities. Oxford and Princeton: Princeton University Press.

Storper, M., \& Scott, A. (2009). Rethinking human capital, creativity and human growth. Journal of Economic Geography, 9.

Todaro, M. (1980). Internal migration in developing countries: a survey. In Population and economic change in developing countries (pp. 361-402). University of Chicago Press.

Widener, M., Metcalf, S., \& Yaneer, B. -Y. (2013). Agent-based modeling of policies to improve food access for low income populations. Applied Geography, 40, 1-10.

Zentella Chávez, A.P. (n.d.). Trayectorias y condiciones de vida de jóvenes mazatecos migrantes en la ciudad de México. Una perspectiva de género, de etnicidad y de clase social. Recuperado de http://s3.amazonaws.com/academia.edu.documents/36390063/ Zentella_2013_JovenesMazatecosMigrates_cd.Mex.pdf?AWSAccessKeyId=AKIAIW OWYYGZ2Y53UL3A\&Expires $=1500080571 \&$ Signature $=$ syDNbbY5NJYby6GbHy0 h\%2F8w7SNc\%3D\&response-content-disposition=inteline\%3B\%20filename\%3DTra yectorias_y_condiciones_de_vida_de_jo.pdf 